\title{
Urban tunnelling in mixed soil conditions: A study of tunnelling works in Bangalore metro rail project, India
}

\author{
Subrahmanya Gudge \\ Bangalore Metro Rail Corporation Ltd, \\ Bengaluru, India \\ gudge@bmrc.co.in
}

\begin{abstract}
Carrying out civil works related to development of infrastructure towards Public Transport System is a challenging task in the present-day urbanization condition. Such Works in City like Bangalore where there is acute shortage of space and Geology controls the progress of construction of metro rail corridor. Bangalore Metro Rail Corporation Ltd. (BMRCL), taken responsibility for implementing Bangalore Metro Rail Project and faced several difficulties in implementing First Phase of this project. One of such challenges was construction of Tunnels and Underground Stations. Tunneling in mixed strata, below major roads and old buildings influenced the progress. Tunneling in ground filled with huge boulders and excavating very hard rock by controlled blasting for station excavation were some of such difficult works. Let us understand the challenges faced and solutions found for Tunneling and Station excavation.
\end{abstract}

Keywords-Mixed soil; Metro rail; tunneling

\section{I.INTRODUCTION}

Tunnelling: Tunnels are being constructed even from the age of Mahabharata. Vidura, the minister of King Dratharashtra arranged to dig a tunnel as an escape route for Pandava princes to save them against an attempt hatched to kill. In modern India, large number of Tunnels were constructed in $760 \mathrm{~km}$ long Konkan Railway which was constructed between 1990 \& 1998. Konkan Railway has 93 Tunnels, all of them are constructed by conventional method expect one Tunnel in Honnavara, Uttara Kannada District, Karnataka State which was constructed by using an open shield. Tunnel Boring Machines were extensively used first time in India in Delhi Metro Project (Phase-1) and subsequently in many other metros as well as in other works related to irrigation, hydro power projects, disposal of sanitary water \&drinking water supply.

Tunnelling by using Tunnel Boring Machines is a very safe tunnelling method which has brought drastic improvement in Tunnelling works. Earlier machines were of open type wherein shield is used only as a support from soil collapse but face is open. Excavation in this type takes place with help of conventional machines like excavator. Pressure at face of the tunnel cannot be increased in open type machines. In rocky strata, which does not need lining as support, open type machine called Gripper TBM with cutter head is used. Such machines will not have shield. There are two types of Machines in closed shield method, one is Earth pressure balancing machine and the other is slurry machine. Before knowing about these machines, it is essential to know the working of a closed type TBM.

A closed type system consists of a horizontal thick steel cylinder which is known as shield. The shield protects machinery and technicians against the earth above. A cutterhead where cutting tools are placed will be on one end of shield towards tunnel face. Cutter head is heavyset part of TBM. Cutting disks and scrappers are placed in the cutter head. Design of cutter head is mainly based on type of earth to be excavated by the machine. A machine to work in soil will not have cutter disks but only scrappers. A machine to work in rocky strata will have cutter disks mounted in cutter head. There will be suitable number of drive motors for rotating the cutter head. There will be a segment erector which is used to place the tunnel lining segments. There are suitable number of thrust jacks which are responsible for pushing the machine ahead. Tunnel lining can be of concrete or steel; concrete being widely used. As regard to removal of excavated muck, there is major difference between Slurry type TBM and Earth Pressure Balancing type TBM, which are explained below.

\section{II.SLURRY TYPE TUNNEL BORING MACHINE}

In slurry type machine, excavation takes place in presence of a liquid known as Tunnelling mud which will have specific gravity of 1.12 to 1.2 . The liquid can be made by using bentonite clay or using polymers. The Tunnelling mud is pumped through a pipe to the excavation chamber. Excavation by TBM happens due to rotation of cutter head and forward movement of shield with help of Thrust Jacks. The tunnel mud or slurry is kept under required pressure to create a continuous support to face of excavation. The excavated stuff along with slurry will be taken out to slurry plant in another pipe. During working of TBM the slurry is continuously circulated between slurry plant and excavation chamber. In slurry plant, the excavated stuff is separated from slurry in gravel separator, sand separator and silt separator. The slurry is re-circulated. Fig $1 \& 2$ show section of a slurry type TBM. Fig. 3 shows section of a EPB type TBM. 


\section{III.EARTH PRESSURE BALANCING MACHINE}

In an earth pressure Balancing machine, the excavation chamber is always kept filled with excavated stuff and excess excavated material is taken out with help of a screw conveyor. The excavation chamber is kept under suitable pneumatic pressure to avoid entry of water into the chamber. Foam is injected through some nozzles in the cutter head to keep the excavated stuff cohesive so that the same moves smoothly in the screw conveyor.

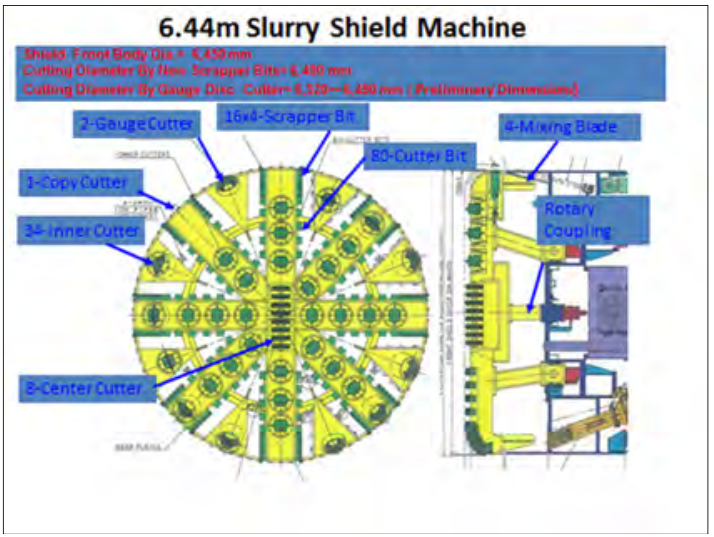

Fig.1. Cutter head and Excavation Chamber of a slurry type TBM.

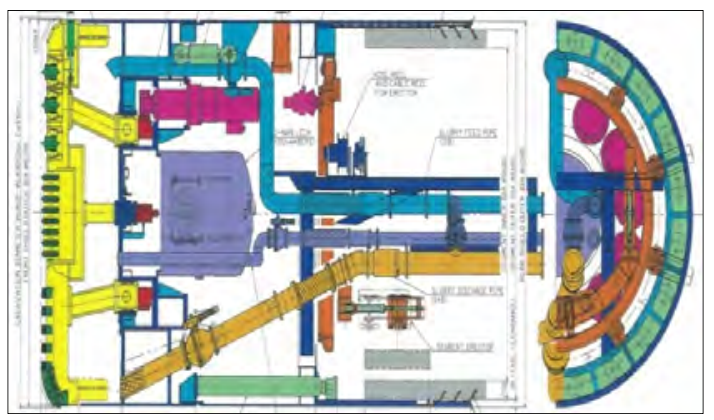

Fig.2. L-Section of a slurry type TBM.

Except above said difference of removing excavated stuff through slurry or screw conveyor, other arrangements in both type of TBMs almost match. Two types of Forces are applied by TBM for excavation. One is to rotate the cutter head (torque) and the other is to push the shield (Thrust).

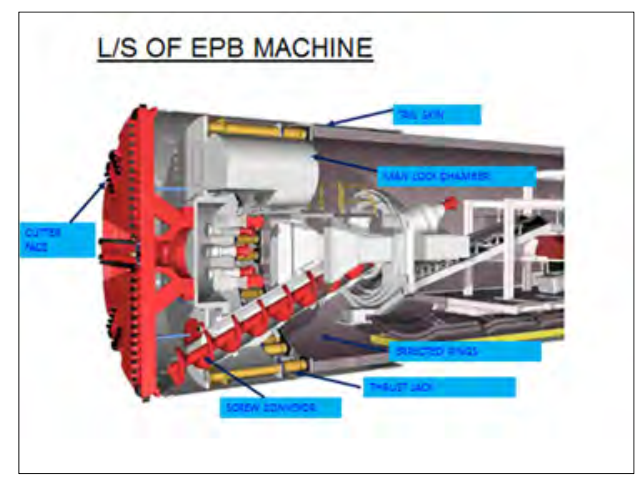

Fig.3. L-Section of an EPB type TBM.
Combination of these two forces is used for excavation in Rock or soil. Face is kept under pressure to keep the water away from entering the machine. If there is loss of water from the area near by the tunnel alignment, water table in the vicinity will be affected which will cause settlement at the surface. The settlement will affect stability of buildings, roads or any other structure existing in the surface. Therefore, keeping the face under suitable pressure is essential.

While excavating the rock, revolution of cutter head is kept higher. The cutter head can rotate upto 4.5 revolutions per minute. Thrust force will be kept low. In case of excavating soil, revolution of the cutter head will be kept low and thrust force will be kept high.

In case of mixed strata, both the above guidelines cannot be met. When face is partially rock and partially soil, the guidelines gets violated with respect to rock or soil. It is difficult to cut the rock with lower revolution and at the same time soil gets excavated quickly and the face needs to stand on its own for longer period, which may cause collapse of face. Damage to cutting tools is more likely while negotiating mixed strata. Figure 4 shows a new tool and a damaged tool. Careful movement of the machine, close observation of various parameters like face pressure, advance rate, theoretical and actual excavation quantity etc. are very essential while mixed face is encountered.

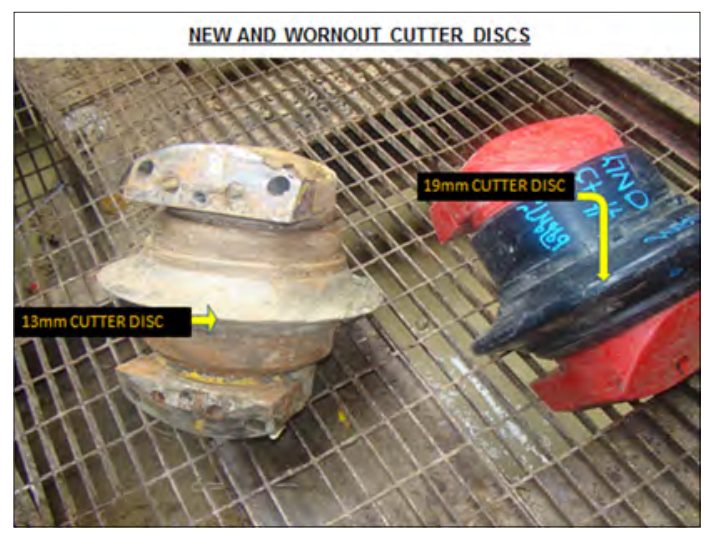

Fig.4. New and worn out Cutter Discs

In case where boulder having diameter/size that of TBM has to be negotiated, the challenge faced by the tunnelling team goes tough. Water moves along the surface of the boulder during increase or decrease in surrounding water table. Fine particles along the surface of the boulder are subjected to moving water repeatedly and get washed away. Mainly course grained particles remain in the area causing loss of friction between surrounding soil and the boulder. Therefore, boulders tend to rotate when cutter head touches it rather than getting cut. The rotation/ movement ofthe boulder causes lot of vibration in the surrounding soil mass resulting ground settlement and damage to structure above. Movement of the boulder also cause pressure loss at face of the tunnel, especially in case of EPB type machine. Slurry may leak to surface in case of slurry machine. Once the boulder becomes loose, it is not safe to continue mining (excavation). 
The loose boulder needs to be arrested in its position by cement grouting from surface. Some Tunnel Boring machine has arrangements to grout from face but this method of injecting the cement grout, it is very essential to protect the cutter-head from the grout. The cutting chamber will be emptied of all the excavated muck and will be filled with a slurry of Bentonite $(90 \%)$ and cement $(10 \%)$. The mix is allowed to set for 8-10 hours. Once the mix is set, cement grouting around the boulder from the surface will be carried out. When grouting is done into the soil, there is little control over the volume. Also, the grout will find way into near by sanitary lines and open drains. A close watch on such utilities is very essential. Grouting may take considerable time depending on the type of soil around the boulder. The machine can restart excavation/mining after 24-48 hours of completing the grouting work as the injected cement grout needs to set and gain at least minimum strength.

Several such situations were met while tunnelling in first phase of Bangalore Metro Rail Project where repeated grouting was required to negotiate such areas with boulders. It has also been noticed that a boulder in front of cutterhead causes considerable damage to cutter disks and other tools mounted on cutter head. Process of placing the damaged tools is known as cutter head intervention. In this process technicians enter the cutter head portion under compressed air. When tunnel alignment is below water table, working under pressure becomes essential to prevent water entering cutter head. If there is air loss happening due to disturbance of boulder, pressure cannot be maintained. In such condition, filling the weak mix into the chamber will be taken up immediately and intervention will be done after completing cement grouting in the area. Initially, a weak mix is filled / injected from the machine itself to surround the cutter head so that cement grout do not come directly in contact with the machine. Once this grout is set; usually in 8-10 hours, cement grouting surrounding the boulder can be done from the surface. Consumption of grout depends on the porosity of the ground in the area. As shape of the boulder cannot be assessed correctly, the grouting has to be carried out almost with a trial and error method. When the area is surrounded by structures / buildings, grouting from the surface will not be possible unless the building is vacated.

Tunnelling becomes further difficult when there are multiple boulders in front of cutter head. Quantum of disturbance at the surface due to movement of boulders will be much more in case of multiple boulders (Fig. 5) than that in case of single boulders. Damage to cutting tools also will be more. Arresting the boulders from further movement is also more difficult than in the case of single boulder. Boulders will not be of regular shape and injecting grout material in such a way that sufficient grout quantity reaches the gap between the boulders is a difficult task. Further, there is no method to assess correct position \& size of the boulders, grouting has to be done only based on observation of Tunnel face from the cutting chamber wherein boulders and type of soil surrounding the boulder can be seen. Fig. 6 shows duration of tunnelling and Fig. 7 shows cutting face

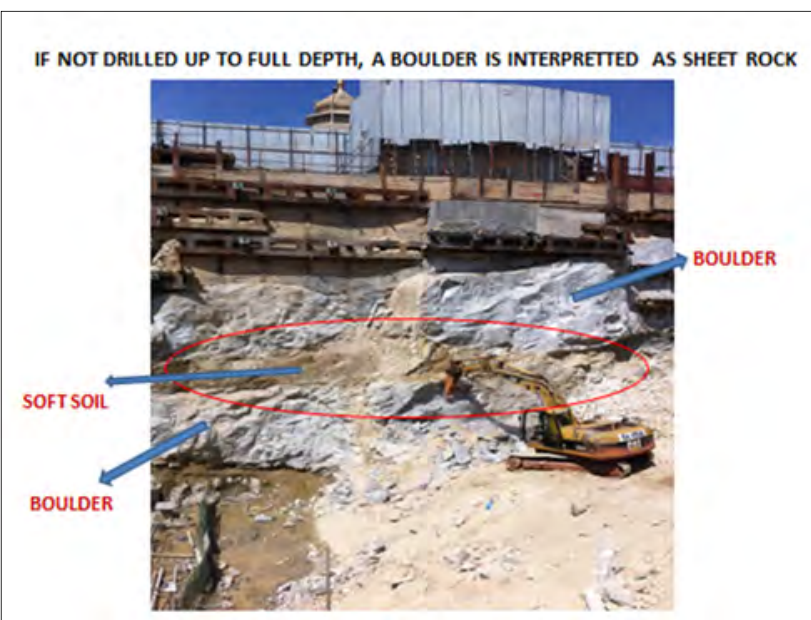

Fig.5. Multiple boulder as seen in Excavation for Vidhana Soudha Station (EW Corridor)

\begin{tabular}{|r|l|c|c|}
\hline S1No & \multicolumn{1}{|c|}{ Description } & TBM-1 (Helen) & $\begin{array}{c}\text { IBM 2 } \\
\text { (Margarita) }\end{array}$ \\
\hline 1 & Length of Tunnel(M) & 715.5 & 718.5 \\
\hline 2 & No of Rings & 477 & 479 \\
\hline 3 & Date of Launching & $14-$ May-12 & $18-J u n-12$ \\
\hline 4 & Date of break through & $26-$ Dec-12 & 20-Feb-13 \\
\hline 5 & Total Time taken in days & 205 & 223 \\
\hline 6 & Intervention Time taken (days) & 75.82 & 89.14 \\
\hline 8 & Number of lnterventions & 100 & 103 \\
\hline 9 & Total Disc changed & 381 & 349 \\
\hline
\end{tabular}

Fig.6. Tunneling duration at Central college-Vidhana Soudha

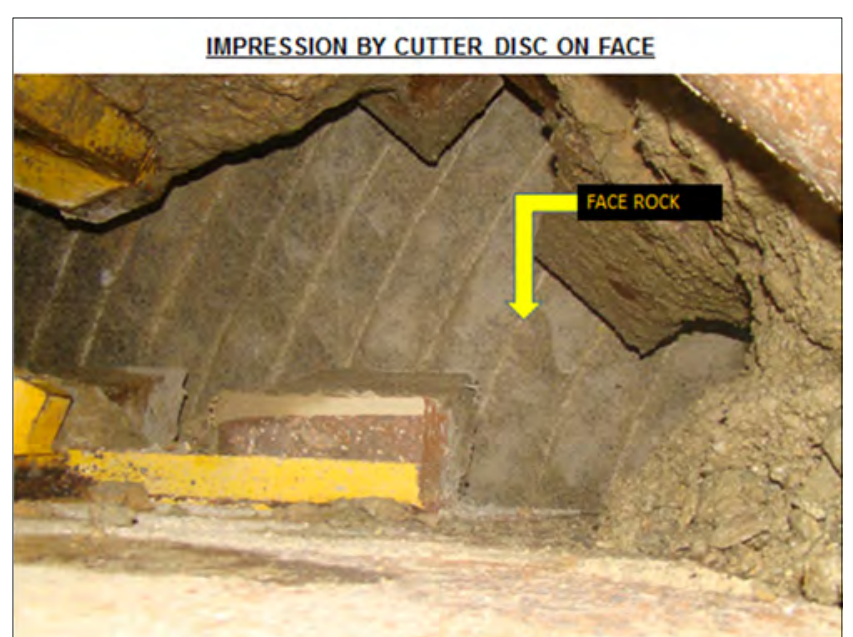

Fig.7. Tunnelling in Hard Rock. Observe the impression by Cutter Disk.

of tunnel in hard rock in front of Vidhana Soudha along east west direction. corridor of Bangalore Metro where multiple boulders are seen.

Boulders faced during tunnelling are of granite rock which is as hard as sheet rock. Compressive strength of bolder / rock encountered is as high as 300mpa. Cutting a granite boulder with strength of $300 \mathrm{mpa}$ is much more difficult than cutting full face rock. 


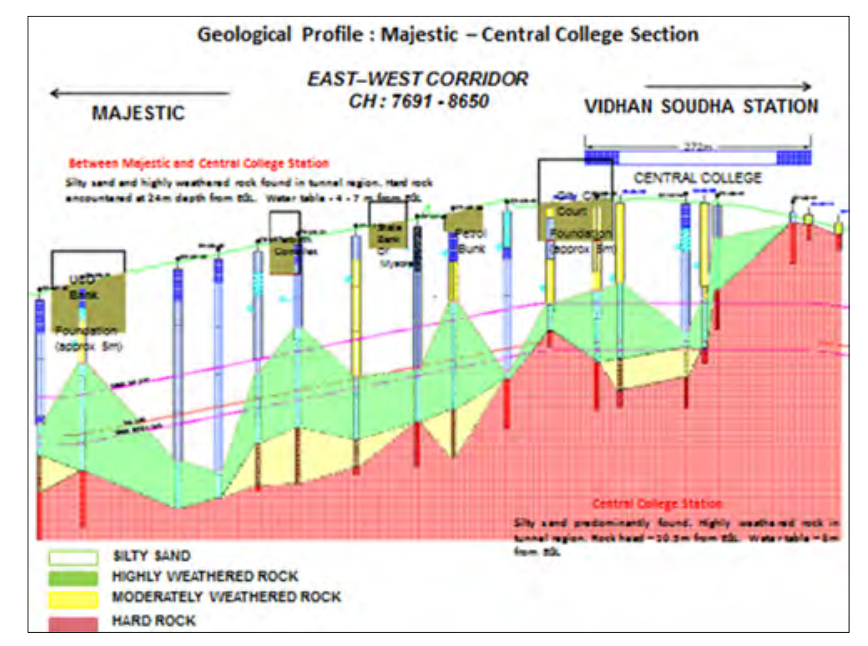

Fig.8. Soil investigation details do not show presence of boulder.

Damage to cutting tools is also more in case of multiple boulders. Soil investigations do not show presence of boulder often (Fig. 8). Table below shows number of interventions and cutter discs changed for a drive of $715 \mathrm{M}$ between two station in EW corridor.

There are several instances where in damage to cutting tools were observed just within one rotation of cutter head. All such challenges due to presence of boulders do not have specific solutions. Each situation needs to be studied in detail considering of location of TBM, structures above TBM, presence of water etc.

Above problems faced due to boulders can be overcome if boulders can be located and plotted in soil investigation drawings. Soil investigation is carried out after finalising the metro alignment. In urban area, soil investigation itself is a difficult task. Usually, metro alignment follows the road alignment. Metro alignment deviates from the road alignment mainly due to curve as radius of curvature along metro alignment needs to be larger than that of road alignment or in road junctions. Soil investigation is usually carried out at every $50 \mathrm{~m}$ or at the most can be at every $25 \mathrm{~m}$, Even this close interval will not be able to map the boulders accurately. Also, soil investigation bore will be terminated

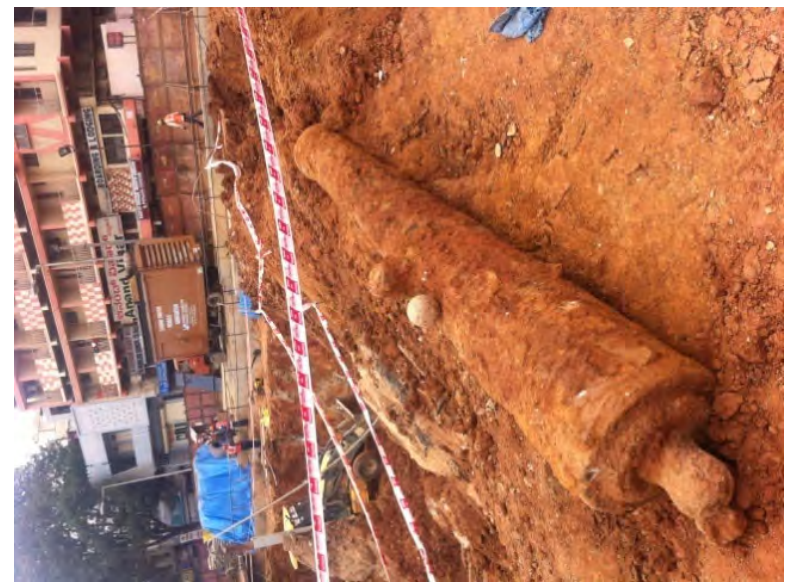

Fig.9. A canon found while station excavation. after drilling one meter in the rock. Strata below that will be recorded as rock in the investigation report/drawing. Sample soil investigation drawing is shown at Fig 8. Not even a single boulder has been identified and recorded anywhere in the soil investigation report of Phase I of Bangalore Metro Project. It is possible to record the complete strata only when the bore is drilled upto depth of proposed alignment irrespective of the depth where rock strata is met. Even in such case also, boulders of size lesser than $25 \mathrm{M}$ will remain unidentified. A boulder of 3-4 M diameter is good enough to pose all the difficulties mentioned in this article.

If there is an alternative method like 'Ultra Sound Technic' or nay other one to record size and depth of boulder accurately, precautionary measures like advance grouting can be done at at least 2-3 months before carrying out Tunnel work so that the grout will attain required strength before the area is subjected to Tunnelling. Even changing the tunnel alignment can be considered depending on the distance of such rock boulders from the nearby station. Two cast iron canons of around $6 \mathrm{M}$ long and $1.2 \mathrm{M}$ diameter were found during excavation of K. R. Market station in North South corridor of Bangalore Metro Rail Project (Fig. 9).

If such a material is met with during tunnelling, there is no alternative than making a rescue shaft to remove such an object which cannot be cut by TBM. A method to find out position of boulders below the ground along a tunnel alignment will be a great tool to Tunnelling Engineers.

\section{ACKNOWLEDGEMENT}

Authors are thankful to the BMRCL authorities for granting permission to publish the paper.

\section{REFERENCES}

[1] BMRCL Technical Reports (internal), 2010-2016 